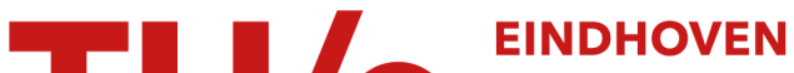 UNIVERSITY OF TECHNOLOGY
}

\section{The influence of solid particles on foam and film drainage}

Citation for published version (APA):

Hudales, J. B. M., \& Stein, H. N. (1990). The influence of solid particles on foam and film drainage. Journal of Colloid and Interface Science, 140(2), 307-313. https://doi.org/10.1016/0021-9797(90)90351-N

DOI:

10.1016/0021-9797(90)90351-N

Document status and date:

Published: 01/01/1990

\section{Document Version:}

Publisher's PDF, also known as Version of Record (includes final page, issue and volume numbers)

\section{Please check the document version of this publication:}

-A submitted manuscript is the version of the article upon submission and before peer-review. There can be important differences between the submitted version and the official published version of record. People interested in the research are advised to contact the author for the final version of the publication, or visit the $\mathrm{DOI}$ to the publisher's website.

- The final author version and the galley proof are versions of the publication after peer review.

- The final published version features the final layout of the paper including the volume, issue and page numbers.

Link to publication

\section{General rights}

Copyright and moral rights for the publications made accessible in the public portal are retained by the authors and/or other copyright owners and it is a condition of accessing publications that users recognise and abide by the legal requirements associated with these rights.

- Users may download and print one copy of any publication from the public portal for the purpose of private study or research.

- You may not further distribute the material or use it for any profit-making activity or commercial gain

- You may freely distribute the URL identifying the publication in the public portal.

If the publication is distributed under the terms of Article 25fa of the Dutch Copyright Act, indicated by the "Taverne" license above, please follow below link for the End User Agreement:

www.tue.nl/taverne

Take down policy

If you believe that this document breaches copyright please contact us at:

openaccess@tue.nl

providing details and we will investigate your claim. 


\title{
The Influence of Solid Particles on Foam and Film Drainage
}

\author{
J. B. M. HUDALES AND H. N. STEIN ${ }^{1}$ \\ Laboratory of Colloid Chemistry, Eindhoven University of Technology, P.O. Box 513, \\ $5600 \mathrm{MB}$ Eindhoven, The Netherlands
}

Received January 22, 1990; accepted May 9, 1990

\begin{abstract}
The effect of hydrophilic glass particles in a cetyltrimethylammonium bromide (CTAB) solution on the drainage and stability of foam and single vertical free liquid films $(0.02 M \mathrm{CTAB})$ in a glass frame was investigated. Large particles (diameter approximately between 1 and $10 \mu \mathrm{m}$ ), being present in the colored films, retard both foam and film drainage and increase film stability. This is ascribed to dispersion of surface waves by particles extending through the film surfaces. Smaller particles $(<1 \mu \mathrm{m})$ lack this property: they shorten film lifetime in foams, although they have no influence on foam drainage. (C) 1990 Academic Press, Inc.
\end{abstract}

\section{INTRODUCTION}

The stability of foams has been investigated (1-15) for a long time. However, a simple and universally accepted measurement for foam stability has never been introduced, although there have been several attempts $(2-4,6,14)$. The present authors investigated foam stability by a method which permitted distinction between influences on film. rupture and film drainage. This method is applied in the present paper to the influence of suspended solid particles on foam.

In many practical situations in which foams (or more generally, thin liquid films) are formed either intentionally or unintentionally, solid particles are present. We mention flotation, foamed concrete, gas mobility control in geological formations in enhanced oil recovery, and coatings. The influence of solid particles on foams is thus a matter of considerable importance.

When surveying the existing literature, we were struck by the lack of information about the influence of hydrophilic solid particles with densities comparable to those encountered in practical situations (e.g., flotation or foamed

${ }^{1}$ To whom all correspondence should be addressed. concrete) with a cationic surfactant as foam stabilizer.

Hydrophobic solid particles, such as finely dispersed silica coated with polysiloxanes (16, $17)$, Teflon $(18,19)$, and hydrophobized glass (19), had been found to destabilize a foam, and therefore these substances may be used as antifoaming agents, e.g., in lubricating oil and washing powder.

The effect of hydrophilic particles, e.g., powdered quartz (20), finely dispersed silica, sulfite cellulose (21), and chalk (22-24), on foams stabilized by anionic surfactants has also been investigated previously. However, the results reported by Sazanov and Taube (20), on the one hand, and those reported by Kruglyakov and Taube (21) and by Portnaya (22) and Portnaya et al. $(23,24)$, on the other, are not mutually comparable, because of the use of solid particles of different densities and porosities.

In this work, measurements of the effect of hydrophilic glass particles in cetyltrimethylammonium bromide (CTAB) solutions on foam stability were supplemented by data on the stability of a single vertical free liquid film in a glass frame and by data obtained on microscopic observations in the latter case. 


\section{EXPERIMENTAL}

\section{Materials}

CTAB was obtained from Sigma Chemical Co. The surface tension vs concentration graph had a distinct break near the $C M C(=9$ $\left.\times 10^{-4} M(25)\right)$ without a minimum; no further purification was applied.

Glass was from Louwers Glass (Hapert, The Netherlands) and consisted of spherical particles with diameter $<10 \mu \mathrm{m}$. The sample was divided into fractions with narrower size distributions by sedimentation in deionized water. Particle size distributions were measured with a Coulter counter; standard deviations ranged from $0.2 \mu \mathrm{m}$ for the fraction with the smallest particles $(<1 \mu \mathrm{m})$ to $2.7 \mu \mathrm{m}$ for the one with the largest $(>5 \mu \mathrm{m})$. Before fractionation by sedimentation the density of the glass particles was determined with a Quantachrome stereopyknometer to be $2.47 \mathrm{~g} / \mathrm{cm}^{3}$.

Water employed in the experiments, other than for sedimentation, was twice distilled.

\section{Apparatus}

Microscope and Fizeau interferometer. The influence of solid particles on the drainage and stability of a single vertical free liquid film was investigated with a Fizeau interferometer and a microscope setup, both described earlier (26, 27). Both setups were equipped with magnetic stirrers to keep the glass particles in suspension between experiments. In the case of the Fizeau interferometer a fan containing the magnet was driven by a jet of thermostatted water; for the microscope a tiny electric motor was builtin in the platform under the sample beaker. During an experiment, from film formation until film rupture, stirring was ceased.

Foam meter. The influence of solid particles on foam stability was investigated with a foam meter (Fig. 1), analogous to the apparatus used by Brady and Ross (4) and Bikerman (6). It consists of a graduated measuring cylinder [9] $50 \mathrm{~cm}$ high and $39 \mathrm{~mm}$ i.d., surrounded by a water jacket through which water

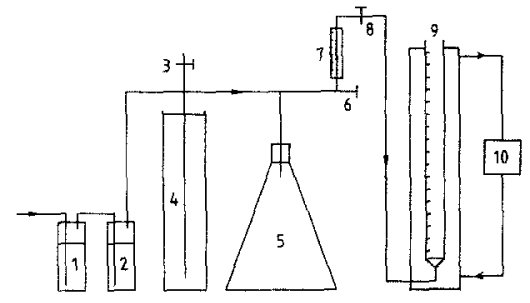

FIG. 1. Schematic representation of the foam meter setup: 1 , washing bottle with $10 \% \mathrm{KOH} ; 2$, washing bottle with some $\mathrm{H}_{2} \mathrm{SO}_{4} ; 3$, deaeration stopcock; 4 , water column; 5 , buffer vessel; 6 , valve; 7 , flow meter; 8 , stopcock; 9 , measuring cylinder; and 10 , thermostat.

at $25^{\circ} \mathrm{C}$ from a thermostatted tank [10] was circulated. Air was blown into the cylinder through a Schott G4 sintered glass filter at the bottom.

Before entering the measuring cylinder [9], the air was passed through two washing bottles containing $10 \% \mathrm{KOH}[1]$ and a trace of $\mathrm{H}_{2} \mathrm{SO}_{4}$ [2], respectively, to remove $\mathrm{CO}_{2}$ and traces of $\mathrm{KOH}$, which might have come with the air out of the first washing bottle. In addition, these washing bottles saturated the air with water vapor, which minimized evaporation inside the foam bubbles. An air outlet in the water column [4] created a constant pressure in the system and prevented the system from possible overpressure (e.g., after terminating the dynamic experiment). A deaeration stopcock [3] over this water column was opened after an experiment to prevent liquid in the second washing bottle from being pressed into the first by the rise of water in the hose in the column [4] after the air pump had been stopped. Small pressure differences in the system were leveled by a buffer vessel [5]. The gas flow, measured by means of a floating-ball flow meter [7], was kept at $50 \mathrm{ml} / \mathrm{min}$. This flow was first established with the valve [6] preceding the flow meter, with $100 \mathrm{ml}$ water in the measuring cylinder, after which the final stopcock [8] was closed. After exchanging the $100 \mathrm{ml}$ water with $100 \mathrm{ml}$ surfactant solution, approximately the same flow was reached when opening the final stopcock [8] again. The surfactant solution was pipetted into the 
measuring cylinder [9]; in doing so, the latter's walls were carefully wetted. Care was taken to prevent the liquid from draining through the glass filter by keeping the pressure under the latter at such values that no foam was created until the experiment was started.

A complete foam meter experiment consisted of a dynamic part and a static part: during the dynamic part air was blown through the sample for $5 \mathrm{~min}$. Time started running at the moment the first air bubbles reached the surface and the liquid height was at its maximum; this height, which was about $2 \mathrm{~mm}$ above the original level, was read $\left(h_{0}\right)$. A 2$\mathrm{mm}$ rise corresponded to $2.4 \mathrm{ml}$ air bubbles in the $100 \mathrm{ml}$ solution. From the time $t=0$ the height of the foam column $\left(h_{2}\right)$ and the height of the liquid/foam interface $\left(h_{1}\right)$ were read alternately every $15 \mathrm{~s}$. There was no need to take any action to keep the particles in suspension, since the rising air bubbles stirred the liquid sufficiently to do so.

The static experiment was started by closing the final stopcock. Time started running at the moment the last bubbles reached the liquid/ foam interface and this interface height was at its minimum. The final values for the dynamic experiment during this lag time of about $10 \mathrm{~s}$ were obtained by extrapolation. The same readings of $h_{1}$ and $h_{2}$ were continued. During this part of the experiment the particles were allowed to settle.

From these readings the height of the foam column $\left(f=h_{2}-h_{1}\right)$ and its liquid $\left(l=h_{0}\right.$ $\left.-h_{1}\right)$ and gas contents $\left(g=h_{2}-h_{0}=f-l\right)$ were calculated as a function of time; heights at a certain time were obtained through linear interpolation, permitting the fraction of liquid in the foam $(l / f)$ to be calculated.

\section{RESULTS}

All experiments described in the present paper refer to suspensions showing no distinct signs of coagulation. In some cases, viz, at very low surfactant concentrations and/or large glass concentrations, coagulation was found, but the suspensions concerned settled too rapidly for experiments on the influence of particles on film stability to be possible.

\section{Microscope}

Observation with a microscope of a free liquid film drawn from a suspension with $10 \%$ $m / m$ solid particles sized between 4 and $5 \mu \mathrm{m}$ showed that some particles are present in the colored film, but could be observed in the film only at a late stage of film history, shortly before the black film arrived at their position. In that stage, no movement of particles in the film toward the vertical plateau borders is observed, but it should be noted that by then transport in the film toward the border is considerably reduced. Instead, at least at such small thicknesses, the particles descend vertically along with the film thickness in which they are embedded; in the black film no particles are observed.

Because of the small film thickness just below the black film, the presence of fairly large particles deforms the film surfaces by protrusion. This makes it very likely that particles influence the lifetime of a foam film by their strong dispersing effect on the surface waves ((28), see also below).

\section{Fizeau Interferometer}

Lifetimes. Lifetimes of single foam films as measured in the Fizeau interferometer showed appreciable scatter; therefore not only average values, but also maximum lifetimes are considered. As in a previous paper (27), a different behavior is observed between frames with legs having sharp-angled and rectangular crosssectional areas; in general, lifetimes of films in a sharp-angled frame are larger than those in a rectangular frame.

Furthermore, lifetimes increase with the addition of small $(2-3 \mu \mathrm{m})$ glass particles in the case of the sharp-angled frame: from 129 \pm 68 to $415 \pm 180 \mathrm{~s}$, showing a significance of $98.5 \%$, while the maximum lifetime increased from 281.5 to $754.7 \mathrm{~s}$. This effect is 
less distinct for the rectangular frame type, where the same solid particles cause an increase from $80 \pm 25$ to $159 \pm 99 \mathrm{~s}$ with a significance of only $82.5 \%$, although the rise in the maximum lifetime is considerable: from 123.3 to $399.8 \mathrm{~s}$. Larger particles $(5-10 \mu \mathrm{m})$ in a rectangular frame showed intermediate values: $126 \pm 54$ and $259.6 \mathrm{~s}$, the first value differing with a significance of about $80 \%$ from the value without particles.

In order to investigate whether some contaminant on the particles, which dissolves in the surfactant solution, causes the lifetimes to increase, after the usual lifetime measurements with a suspension, the particles were sedimented in a centrifuge and lifetime measurements were repeated with the supernatant: the average lifetime is indeed shortened about $50 \%$. This may be due either to removal of surfactant from the liquid by adsorption or to dissolution of a contaminant (e.g., ions) from the glass. Preliminary experiments have shown that both effects occur.

Drainage. The effect of solid particles on the drainage of a single free liquid film was investigated with the Fizeau interferometer, with which film profiles were obtained as described in (27). From the profiles, thicknesses at certain heights above the meniscus $(10,20$, and $30 \mathrm{~mm}$ ) are calculated through linear interpolation (27). From such data the "draining rate" is calculated; this is the horizontal velocity of the front (or back) surface of a film, in the direction perpendicular to the film midplane. The calculation was performed numerically; for this, the data obtained after linear interpolation between the experimental points (see above) were converted to reciprocal half thickness vs time graphs and smoothed by performing a polynomial fit of maximum. power 4 . This resulted in a larger number of points than in the original data. Differentiation was performed through Lagrange's five-point interpolation formulas (29). Draining rates at certain film thicknesses, e.g., $1 \mu \mathrm{m}$, are then obtained by linear interpolation.

In the case of the rectangular frame type the drainage rate decreases by the addition of solid particles, at least with a diameter larger than $4 \mu \mathrm{m}$, from $102.5 \pm 8.7$ to 45.7 and $43 \mathrm{~nm} / \mathrm{s}$ for 4- to $5-\mu \mathrm{m}$ and 5- to $10-\mu \mathrm{m}$ particles, respectively. For the sharp-angled frame type this decrease is less pronounced, although smaller particles are used: from $52.2 \pm 14.9$ to $39.5 \pm 14.4 \mathrm{~nm} / \mathrm{s}$ for $2-$ to $3-\mu \mathrm{m}$ particles and to $44.1 \mathrm{~nm} / \mathrm{s}$ for 3 - to $4-\mu \mathrm{m}$ particles (significance $80 \%$, resp. $70 \%$ ).

\section{Foam Meter}

A typical result of a foam meter experiment is shown in Fig. 2 for a $0.02 M$ CTAB solution without particles: during the first 5 min air was blown into the solution at constant flow, leading to a linear increase of the gas content $(g)$ in the foam with time. The liquid content (l) in the foam column also rises with time, but with much lower velocity. The liquid fraction usually decreases gradually with time.

Some time after the air supply was stopped, the rise of the foam/air interface also ceased. At the surfactant concentration used, a very stable foam was obtained. However, drainage of liquid is shown by the decrease of the liquid content and liquid fraction of the foam. The accuracy of the readings $(0.1 \mathrm{~mm} \sim 119.5$

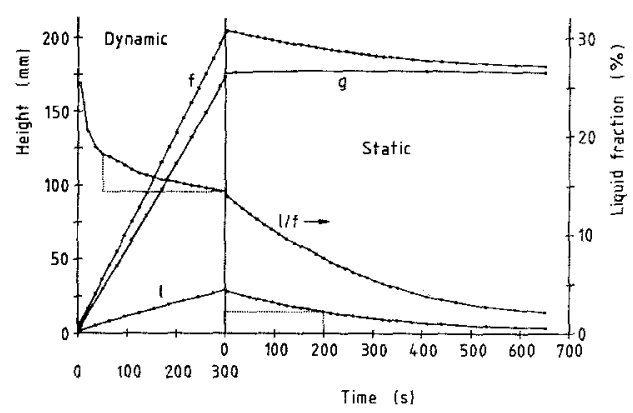

Fig. 2. Results of a dynamic and a static foam meter experiment with $0.02 \mathrm{MCTAB}$ without particles. Indicated are the column heights for the liquid content $(l)$, gas content $(g)$, and foam content $(f)$, as well as the liquid fraction $(l / f)$ in percent. Dotted lines: determination of the DDR and SDT in the dynamic and static parts of the experiment, respectively; TGC is determined by the slope of $g$ during the dynamic experiment. 
$\mathrm{mm}^{3}$ ) did not permit the detection of the amount of liquid in the foam, when most films had become black.

From the dynamic experiments the rising velocity of the foam was calculated by linear regression of the $g(t)$ values. If this velocity equals $0.70 \mathrm{~mm} / \mathrm{s}(\approx 50 \mathrm{ml} / \mathrm{min})$ then all the air blown through the suspension is encysted in the stable foam. The percentage air retained in the foam is referred to as transient gas capture (TGC), which is determined by film rupture of the bubbles at the top of the foam.

The rate of the liquid fraction decrease is predominantly a measure of the drainage during foam formation; the difference in liquid fractions at two arbitrarily chosen times, 50 and $290 \mathrm{~s}$, was divided by the time interval covered ( $4 \mathrm{~min}$ ), yielding the procentual decay rate of the liquid fraction in the film during formation (dynamic decay rate: DDR). The decay time, as used for the static experiment (see below), appeared not to be very practical in this case, since the intake of liquid during foam formation usually prevented the liquid fraction from reaching half its original value during the time the dynamic experiment lasted.

The static experiment supplies us with decay times for the amount of liquid $(l)$ and the liquid fraction $(l / f)$. Time intervals are obtained in which the maximum at the start of the static experiment reduces to half of this maximum (21). The decay time of the liquid fraction always appears to be somewhat larger than that of the liquid content. Both showed the same trends and therefore we mention only the latter magnitude, which is indicated as static decay time (SDT).

In the absence of glass, TGC increases from 49 to about $90 \%$ (Fig. 3), DDR decreases from 16 to $2 \% / \mathrm{min}$ and SDT increases from about 50 to $220 \mathrm{~s}$ while increasing the surfactant concentration from $10^{-4}$ to $0.02 M$ CTAB. The addition of small amounts $(<0.5 \%)$ of small glass particles $(<1 \mu \mathrm{m})$ has no significant effect on DDR and SDT, but decreases TGC at low CTAB concentrations (Fig. 3).

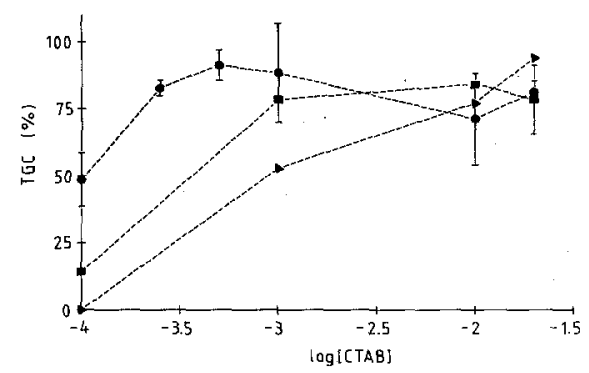

FIG. 3. TGC (the percentage of air encysted in the foam, compared with the total amount of air blown in) as a function of the logarithm of the $\mathrm{CTAB}$ concentration without particles (๑) or with $0.25 \%$ ( $\square$ ) or $0.5 \%(\rightarrow)$ $(\mathrm{m} / \mathrm{m})$ glass particles smaller than $1 \mu \mathrm{m}$; vertical bars, standard deviations.

An increase in the amount of these particles up to $2.5 \%$ in $10^{-4}$ or $10^{-3} M$ CTAB decreases TGC (Fig. 4) and SDT (Fig. 5). However, for larger particles $(<10 \mu \mathrm{m})$ in an intermediate CTAB concentration $\left(5.4 \times 10^{-4} \mathrm{M}\right)$ the theoretical TGC was found over the range of glass amounts added, while SDT increased at high $(2.5 \%)$ glass content. Similar, though less distinct, effects were found for DDR.

\section{DISCUSSION}

Fizeau Interferometer $([C T A B]=0.02 \mathrm{M})$

The difference between a sharp-angled and a rectangular frame has already been discussed in Ref. (27). The larger drainage rate for the rectangular frame is explained by the larger cross-sectional area of the plateau border for the rectangular frame as compared with the sharp-angled frame, which permits more liquid to flow through. This drainage increase is accompanied by a shorter lifetime of the film.

Drainage of separate films is retarded by glass particles, at least if they are larger than the average film thickness (27). This effect can be ascribed to the dispersion of surface waves, which cause marginal regeneration (27). In agreement with this statement is the increase in lifetime of separate films: film rupture is connected with the occurrence of surface waves as well (28). It is true that surface waves 
leading to film rupture occur in black films, in which no solid particles are observed. However, surface waves in the black film will continue in the colored film (and vice versa), thus dispersion of surface waves in the colored film is expected to lead to a smaller amplitude of surface waves in the black film.

\section{Foam Meter}

Of the three criteria on the stability of foams in the foam meter, the TGC is determined by the lifetimes of films on top of the foam, while the DDR and SDT are determined by both drainage and rupture. Film rupture, taking place spread equally over the center of the foam, causes larger bubbles and drainage of the excess liquid from the ruptured film, but the amount of gas in the foam remains constant; film rupture on top of the foam only means loss of gas, which, however, is accompanied by a negligible increase in the drainage.

According to the foam meter results (cf. Fig. 3 ), foam stability increases with increasing $\mathrm{CTAB}$ concentration in the absence of glass particles. Indeed, at low CTAB concentration the film lifetime is short, as observed when trying to form separate films in the Fizeau interferometer.

Small particles are found to promote film rupture to a limited extent at low CTAB concentrations (Fig. 3). As an explanation, one

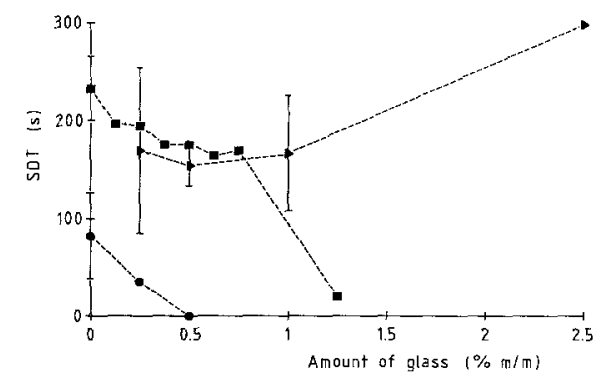

FIG. 4. SDT as a function of the amount of glass added to the sample. (•) $10^{-4} M \mathrm{CTAB}+$ particles $<1 \mu \mathrm{m},(\square)$ $10^{-3} M \mathrm{CTAB}+$ particles $<1 \mu \mathrm{m},(\downarrow) 5.4 \times 10^{-4} \mathrm{M}$ $\mathrm{CTAB}+$ particles $<10 \mu \mathrm{m}$; vertical bars, standard deviations.

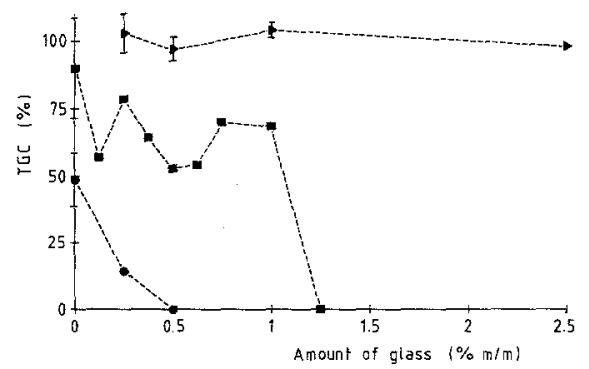

FIG. 5. TGC as a function of the amount of glass added to the sample. For an explanation of the labels see the legend to Fig. 4.

might think of the lowering of the CTAB concentration through adsorption on the glass particles.

Large particles act differently: the SDT increases rather than decreases (Fig. 4). This difference is ascribed to part of the glass particles having diameters exceeding the average film thickness. When present in a film, as observed with the microscope, they will disperse surface waves and counteract both drainage and rupture. Even at a CTAB concentration of 5.4 $\times 10^{-4} \mathrm{M}$, the TGC may approach the value for total gas capture (Fig. 5). Apparently, in foams a stabilizing effect by large particles occurs that is similar to the one observed in the case of separate thin liquid films in the Fizeau interferometer. The surface area of the larger glass particles is too small to lead to a signifcant decrease in surfactant concentration.

Sazanov and Taube (20) explain the destabilizing action of quartz on foams formed in sulfonol solutions by adsorption of the surfactant on the quartz, leading to depletion of the liquid with regard to the sulfonol. Indeed, it is known that CTAB is adsorbed on glass surfaces, as shown by coagulation of the glass particles in the case of small CTAB concentrations and large amounts of small glass particles; however, at the higher CTAB concentrations used, the total glass surface area is too low to lead to any surfactant depletion of the solution. The destabilizing action found by Sazanov and Taube in the case of small sur- 
factant concentration is found in the present investigation also, for glass particles smaller than $1 \mu \mathrm{m}$. For larger particles we found a stabilizing effect; comparison with the results mentioned by Sazanov and Taube $(20)$ is not possible, because of the lack of data on the size of the quartz particles employed by them.

\section{CONCLUSIONS}

Hydrophilic suspended particles smaller than $1 \mu \mathrm{m}$ shorten the lifetime of films in foams. Larger particles (up to $10 \mu \mathrm{m}$ ) stabilize films in foams against rupture and decrease their drainage. This is confirmed by measurements of drainage and lifetime of separate films. This difference is explained by dispersion of surface waves by particles protruding into the film surfaces.

\section{REFERENCES}

1. Foulk, C. W., and Miller, J. N., Ind. Eng. Chem. 23, 1283 (1931).

2. Bikerman, J. J., Trans. Faraday Soc. 34, 634 (1938).

3. Clark, G. L., and Ross, S., Ind. Eng. Chem. 32, 1594 (1940).

4. Brady, A. P., and Ross, S., J. Amer. Chem. Soc. 66, 1348 (1944).

5. Ross, S., J. Phys. Chem. 50, 391 (1946).

6. Bikerman, J. J., "Foams: Theory and Industrial Applications," Chap. 2. Reinhold, New York, 1953.

7. De Vries, A. J., dissertation, Utrecht, 1957.

8. Kitchener, J. A., and Cooper, C. F., Q. Rev. 13, 71 (1959).

9. Kruglyakov, P. M., and Taube, P. R., J. Appl. Chem. USSR 38, 1483 (1965) (Translation from $Z h$. Prikl. Khim. 38, 1514 (1965)).

10. Kruglyakov, P. M., and Taube, P. R., J. Appl. Chem. USSR 39, 1403 (1966) (Translation from $Z h$. Prikl. Khim. 39, 1499 (1966)).

11. Exerowa, D., Khristov, Khr., and Penev, I., in "Foams, Proc. Symp. Brussel Univ. 1975" (R. J. Akers, Ed.), pp. 109-123. Academic Press, New York, 1976.
12. Khristov, Khr., Kruglyakov, P., and Exerowa, D., Colloid Polym. Sci. 257, 506 (1979).

13. Khristov, Kh.I., Ekserova, D. R., and Kruglyakov, P. M., Colloid J. 43, 80 (1981) (Translation from Kolloidn. Zh. 43, 101 (1981)).

14. Khristov, Kh.I., Ekserova, D. R., and Kruglyakov, P. M., Colloid J. 43, 166 (1981) (Translation from Kolloidn. Zh. 43, 195 (1981)).

15. Khristov, Khr.I., Exerowa, D. R., and Kruglyakov, P. M., Colloid Polym. Sci. 261, 265 (1983).

16. Taube, P. R., Kotova, T. T., and Sazanov, V. A., Sb. Nauchn. Rab. Penz. Inzh. Stroit. Inst. 7, 119 (1970).

17. Ross, S., and Nishioka, G., in "Emulsions, Latices and Dispersions" (P. Becher and M. N. Yudenfreund, Eds.), pp. 237-256. Dekker, New York, 19.78.

18. Garrett, P. R., J. Colloid Interface Sci. 69, 107 (1979).

19. Frye, G. C., and Berg, J. C., J. Colloid Interface Sci. 127, 222 (1989).

20. Sazanov, V. A., and Taube, P. R., Sb. Nauchn. Rab. Penz. Inzh. Stroit. Inst. 7, 128 (1970).

21. Kruglyakov, P. M., and Taube, P. R., Colloid J. 34, 194 (1972) (Translation from Kolloidn. Zh. 34, 228 (1972)).

22. Portnaya, I. B., deposited document, VINITI 858 862 (1981)

23. Portnaya, I. B., Mazina, G. R., Polukhina, T. I., and Panich, R. M., Colloid J. 43, 482 (1981) (Translation from Kolloidn. Zh. 43, 592 (1981)).

24. Portnaya, I, B., Suchkova, L. N., Novgorodova, S. N., and Panich, R. M., Colloid J. 43, 718 (1982) (Translation from Kolloidn. Zh. 43, 883 (1981)).

25. Vassiliades, A. E., in "Cationic Surfactants" (E. Jungerman, Ed.). Chap, 12. Dekker, New York, 1970.

26. Hudales, J. B. M., and Stein, H. N., J. Colloid Interface Sci., in press.

27. Hudales, J. B. M., and Stein, H. N., submitted for publication.

28. Vrij, A., and Overbeek, J. Th. G., J. Amer. Chem. Soc. 90, 3074 (1968).

29. Hoerl, A. E., Nashed, M. Z., McKetta, J. J., and Silberberg, J. H., in "Perry's Chemical Engineer's Handbook" (D. W. Green and J. O. Maloney, Eds.), 6th ed., pp. 2-65. McGraw-Hill, New York, 1984. 